NASA Technical Memorandum 104372

\title{
Polymeric Routes to Silicon Carbide and Silicon Oxycarbide CMC
}

Frances I. Hurwitz

Lewis Research Center

Cleveland, Ohio

and

Paula J. Heimann, John Z. Gyekenyesi, John Masnovi, and Xin Ya Bu

Cleveland State University

Cleveland, Ohio

Prepared for the

15th Annual Conference on Composites and Advanced Ceramics sponsored by the American Ceramic Society

Cocoa Beach, Florida, January 13-16, 1991

\section{N/SA}




\title{
POLYMERIC ROUTES TO SILICON CARBIDE AND SILICON OXYCARBIDE CMC
}

\author{
Frances I. Hurwitz \\ National Aeronautics and Space Administration \\ Lewis Research Center \\ Cleveland, Ohio 44135 \\ and \\ Paula J. Heimann, * John Z. Gyekenyesi, * \\ John Masnovi and $\mathrm{Xin} \mathrm{Ya} \mathrm{Bu}$ \\ Cleveland State University \\ Cleveland, oh
}

SUMMARY

An overview of two approaches to the formation of ceramic composite matrices from polymeric precursors is presented. Copolymerization of alkyl- and alkenylsilanes $\left(\mathrm{RSiH}_{3}\right)$ represents a new precursor system for the production of $\beta$-sic on pyrolysis, with copolymer composition controlling polymer structure, char yield, and ceramic stoichiometry and morphology. Polysilsesquioxanes which are synthesized readily and can be handled in air serve as precursors to Si-C-o ceramics. Copolymers of phenyl and methyl silsesquioxanes display rheological properties favorable for composite fabrication; these can be tailored by control of pH, water/methoxy ratio and copolymer composition. Composites obtained from these utilize a carbon coated, eight harness satin weave Nicalon cloth reinforcement. The material exhibits

nonlinear stress-strain behavior in tension.

\section{INTRODUCTION}

The use of polymeric precursors to ceramics enables the fabrication of complexshaped ceramic matrix composites (CMCs) using low processing temperatures and technology currently available for the fabrication of resin matrix composites. Several polymeric systems are under investigation at NASA Lewis Research Center as candidates for CMC matrix precursors. Two of these will be reviewed here: the polymerization of alkyl- and alkenylsilanes as precursors to nonoxide si-c materials, including crystalline SiC (Part I), and the synthesis of polysilsesquioxanes which yield Si-C-O ceramics on pyrolysis (Part II). The silane polymerization and subsequent composite fabrication requires handling under inert conditions. By contrast, the polysilsequioxanes are handled readily in air, making them preferable for use in developing fabrication techniques. In both polymer systems, copolymerization is used to control polymer properties as well as ceramic stoichiometry.

The Si-C-O ceramic would be of benefit as a CMC matrix for use in the intermediate (900-1200 ${ }^{\circ} \mathrm{C}$ ) temperature range, while the route to sic would benefit high $\left(>1200{ }^{\circ} \mathrm{C}\right)$ temperature applications. 
The polymerization of alkylsilanes utilizing a dimethyltitanocene catalyst has been demonstrated by Harrod and coworkers (refs. 1 to 5) to yield a polysilane (-Si-Si- backbone) with the evolution of hydrogen. However, when an unsaturated carbon bond is present in the monomer, as is the case in vinylsilane, polymerization using the same titanocene catalyst produces a mixture of polysilane and polycarbosilane (-Si-C- backbone), with the polycarbosilane as the dominant product (refs. 6 and 7). Also, hydrogen addition across the vinyl double bond occurs during polymerization. Three polymerization mechanisms are proposed to explain this result: metathesis, dehydrogenative coupling and hydrosilation (fig. 1), with hydrosilation appearing to be the dominant reaction path.

A number of different alkyl- and alkenylsilanes have been polymerized, including methyl-, ethyl-, allyl- and vinylsilanes. We also have copolymerized methyl- and vinylsilane using several mole ratios of the two monomers, and compared the resulting ceramics with those produced from blends of the homopolymers. The polymer backbone structures, determined by ${ }^{29} \mathrm{Si} \mathrm{NMR}$, char yield on pyrolysis in argon to $1400{ }^{\circ} \mathrm{C}$ at $10^{\circ} / \mathrm{min}$, with the final temperature maintained for 30 min, and ceramic morphology, obtained by x-ray diffraction, are summarized in table I.

Polymerization of either ethyl- or methylsilane produces polysilane exclusively. Allylsilane polymerization yields a mixture of polysilane and polycarbosilanes in a ratio of 80:20. By contrast, vinylsilane produces more of the polycarbosilane structure. Comparison of char yields for the polymers of ethyl-, allyl-, vinyl- and methylsilane shows char yield to increase with carbosilane backbone structure, with the exception of polymethylsilane which, although exclusively a polysilane, has the highest char yield of the homopolymers. One possible explanation is that the methyl group inserts in the backbone to form a polycarbosilane during pyrolysis, as has been demonstrated by Yajima (ref. 8) to occur on pyrolysis of polydimethylsilane.

Copolymerization of methyl- and vinylsilane produced polymers with mixed polysilane and polycarbosilane backbones, with the percentage of polysilane increasing with methyl/vinyl ratio. Char yields ranged from 61 to 73 percent, and increased with methyl content beyond the 68 percent attained from the polymerization and pyrolysis of methylsilane alone. Blends of methyl + ethyl, ethyl + vinyl and methyl + vinyl derived polymers exhibited backbone structures in ratios that would be predicted based upon the rule of mixtures. Of these, the methyl + vinyl polymer blend showed the highest char yield, 71 to 72 percent. However, unlike the methyl/ vinyl copolymers, the blend was insoluble, and thus not suitable for composite fabrication.

The ethylsilane derived ceramic was x-ray amorphous, while the allyl- and vinylsilane derived materials, though predominantly amorphous, exhibited minor phases of $\beta$-sic. The methyl/vinyl copolymers were characterized by increasing degrees of crystallinity and crystallite size with increasing methyl content. The largest $\beta$-sic crystallites (140 A) were obtained from the methyl polymer. This polymer also produced crystalline Si as a minor phase. The presence of free Si is considered to be undesirable in a CMC matrix, as it might react with fibers during processing. It also could lead to creep, as well as enhanced oxidation in the final composite. The methyl + ethyl polymer blend also showed a minor Si phase. All blends were characterized by the presence of $\beta$-sic. 
Elemental analysis of the ceramic products using combustion techniques was employed for the determination of $\mathrm{Si}$ and $\mathrm{C}$. We consider the Si determination to be reliable. However, carbon determination is complicated by the formation of sio on combustion in air, which leads to underestimation, and dependence of the analysis on relative surface area (i.e., the amount of carbon found increases as particle size is decreased by grinding). Use of higher combustion temperatures (induction furnace method) typically increases C values, but does not eliminate the problem. Some of the polymers also exhibited considerable moisture sensitivity, particularly the polymer of ethylsilane, which would lead to oxygen incorporation and values of si plus $C$ of considerably less than 100 percent. Moisture sensitivity was observed to decrease as polycarbosilane formation increased.

Results of elemental analyses are summarized in table II. Stoichiometric SiC is 70 percent Si, 30 percent $\mathrm{C}$ by weight. On the basis of the Si determination, the methylsilane polymer and methyl + ethyl polysilane blends are closest to stoichiometric Sic; however, both also contain free si. The methyl/vinyl copolymers and methyl + vinyl polymer blends produce ceramics containing $63-66$ percent si by weight, and thus would be candidates as precursors to sic. Of these, the 75 methyl/25 vinyl copolymer is the precursor of choice for formation of crystalline sic, based on a combination of solubility, ceramic stoichiometry, crystallite size and char yield (see tables I and II). The vinylsilane polymer also might be considered as a candidate for producing a carbon-rich, amorphous ceramic.

\section{Part I: CONCLUSIONS}

The present work demonstrates that dimethyltitanocene can be as a catalyst used to polymerize alkenylsilanes, in addition to its use in the polymerization of alkylsilanes, as described by Harrod and coworkers (refs 1 to 5). Photoinitiation (ref. 7) permits use of low (mM) concentrations of catalyst. Polymerization of alkylsilanes is found to produce polysilanes, whereas that of alkenylsilanes gives rise to a mixture of polysilane and polycarbosilane backbone structures.

On the basis of the results obtained here, the methyl/vinyl copolymers have been selected as candidates for composite fabrication based upon high char yield, high sic yield, and the potential for tailoring copolymer composition to obtain either stoichiometric SiC or carbon-rich matrices. The vinylsilane derived polymers also are being investigated for composite fabrication, and would be expected to produce a carbon-rich matrix.

Future work will be focused on establishing methods for composite fabrication and controlling ceramic stoichiometry and morphology through control of copolymer composition and backbone structure. Work also is ongoing to establish an understanding of the polymerization mechanisms using radiolabelling techniques, so as to better tailor polymer structure to optimize the conversion to ceramic.

Many of the polymers produced have exhibited low viscosities. It therefore might be desirable to develop crosslinking groups to control polymer rheology during the composite fabrication process. Disilylethane is one such crosslinking group which has been synthesized successfully; its use in optimizing rheology is under study. 


\section{Part II: POLYMERIZATION AND PYROLYSIS OF POLYSILSESQUIOXANES}

Homo- and copolymers of phenyl- and methylsilsesquioxanes were synthesized by hydrolysis and condensation of their trimethoxysilane monomers in acid solution (ref. 9). A schematic of the reactions involved is shown in figure 2 . Synthesis variables included $\mathrm{pH}$, water to methoxy ratio and phenyl to methyl monomer ratio.

The influence of synthesis conditions on polymer structure was determine by ${ }^{29} \mathrm{Si}$ NMR, as described in detail elsewhere (ref. 9). For a polymer having the structure $\mathrm{RSi}(\mathrm{O}-)_{\mathrm{x}}(\mathrm{OH})_{3-\mathrm{x}^{\prime}}$ relative quantities of mono- $(\mathrm{x}=1)$, di- $(\mathrm{x}=2)$ and trifunctional ( $\mathrm{x}=3$ ) Si atoms can be established by peak integration. Occurrence of difunctional silicon (cyclic or linear polymer formation) was observed to increase with water to methoxy ratio, and was accompanied by a decrease in branching, as shown in figure 3. At low water/methoxy values $(<1)$, gelation occurs, while at higher values ( 8 to 16) a polymer which is more linear, and better suited to composite fabrication, could be obtained.

Branching (or crosslinking) also was found to decrease on increasing $\mathrm{pH} f r o m 2$ to 3 (fig. 4), as evidenced by a decrase in the number of trifunctional groups. The polymer formed at pH 2 was presumed to have a high cyclic content, as evidenced by the absence of many monofunctional Si atoms. The pH 3 material was lowest in viscosity of the polymers obtained over a pH range of 2 to 4 , and was most suitable for composite processing.

The influence of copolymer composition on polymer structure is illustrated in figure 5. Polymethylsilsesquioxane exhibits a high degree of crosslinking or cyclic structure. As phenyl groups are incorporated in the polymer, the number of trifunctional Si atoms decreases, and the polymer becomes more linear, and less viscous. The char yield also has been found to decrease with increasing phenyl content; this may be explained, at least in part, by the change in backbone structure. The incorporation of phenyl groups in the polymer also produces an increase in the carbon content of the resulting ceramic char (fig. 6). Therefore, it is expected that polymer rheology, and hence composite fabrication, as well as ceramic matrix properties will be influenced by copolymer composition.

Composites have been fabricated using a carbon coated, eight harness satin Nicalon cloth and 50 phenyl/50 methyl (mole percent) silsesquioxane copolymer. Si-co ceramic matrix composites were obtained by pyrolysis, followed by several reimpregnation/pyrolysis cycles. Eight inch long, straight sided specimens tested in tension exhibited non-linear stress-strain behavior typical of composites having woven reinforcement. A representative stress-strain curve, and typical mechanical properties, are shown in figure 7. Tensile fracture surfaces (fig. 8) were characterized by bundle fracture and some fiber pull-out. At the highest magnification, fibers can be observed to bridge matrix cracks perpendicular to the tensile axis. Closer examination of individual fibers which have pulled out from a tow (fig. 9) shows that matrix fragments are adherent to the fiber surface, indicating that further work is needed to optimize the fiber coating and fiber/matrix interface.

\section{Part II: CONCLUSIONS}

The polysilsesquioxane copolymers provide a facile and inexpensive route to the formation of Si-C-O matrices, proposed for use in the intermediate (900-1200 ${ }^{\circ} \mathrm{C}$ ) temperature range (ref. 10). Copolymer composition, water/methoxy ratio and pH 
control polymer structure, and hence rheological behavior and composite processing. Ceramic matrix composites have been fabricated successfully which exhibit nonbrittle fracture when tested in tension at room temperature.

Future work will center on optimizing fiber coatings and coating thickness, determination of the optimum matrix composition needed to maximize composite mechanical behavior and thermo-oxidative stability, and determination of tensile properties at elevated temperatures.

\section{ACKNOWLEDGEMENTS}

The authors wish to thank Ralph G. Garlick for x-ray diffraction studies, and Terrence A. Kacik and Ann Modock for thermal analysis characterization.

\section{REFERENCES}

1. Samuel, E.; and Harrod, J.F.: Synthesis and Characterization of a Novel Bis(cyclopentadienyl)titanium Hydride Complex, J. Am. Chem. Soc., vol. 106, no. 6, 1984, pp. 1859-1860.

2. Aitken, C.T.; Harrod, J.F.; and Samuel, E.: Polymerization of Primary Silanes to Linear Polysilanes Catalyzed by Titanocene Derivatives, J. Organomet. Chem., vol. 279, no. 11, 1985, pp. C11-C13.

3. Aitken, C.; Harrod J.F.; and Samuel, E.: Identification of Some Intermediates in the Titanocene-Catalyzed Dehydrogenative Coupling of Primary

Organosilanes.J. Am. Chem. Soc., vol. 108, no. 14, 1986, pp. 4059-4066.

4. Harrod, J.F.; and Yun, S.S.; Silyltitanocene Complexes as Catalysts for the Hydrogenation, Isomerization and Hydrosilation of olefins, Organometallics, vol. 6, no. 7, 1987, pp. 1381-1387.

5. Harrod, J.F.: Polymerization of Group 14 Hydrides by Dehydrogenative Coupling, Inorganic and Organometallic Polymers, M. Zeldin, J. R. Allcock, and K.J. Wynne, eds. ACS Symposium Monograph 360, American Chemical Society, Washington, D. C. , 1988, pp. 89-100.

6. Masnovi, J., et al.: Polymerization of Alkenylsilanes Using Early Transition Metal Catalysts. Mat. Res. Soc. Symp. Proc., vol. 180, 1990, pp. $779-784$.

7. Bu, X.Y., et al.: Polycarbosilane from Polymerization of Vinylsilane. Chem. Commun., submitted 1990.

8. Yajima, S., et al.: Synthesis of Continuous Silicon Carbide Fibre with High Tensile Strength and High Young's Modulus," J. Mater. Sci., vol. 13, no. 12, 1978 , pp. 2569-2576.

9. Heimann, P.J.; Hurwitz, F.I.; and Rivera, A.L.: Synthesis of Polysilsesquioxanes for Use as Ceramic Precursors. Symposium on Composites: Processing, Microstructure and Properties, Nov. 12-15, 1990, Orlando, FL, to be published.

10. Greil, P.: Thermodynamic Calculations of Si-C-O Fiber stability in Ceramic Matrix Composites." J. Eur. Ceram. Soc., vol. 6, 1990, pp. 53-64. 
TABLE I. - INFLUENCE OF POLYMER COMPOSITION ON POLYMER STRUCTURE, CHAR YIELD AND CERAMIC MORPHOLOGY

\begin{tabular}{|c|c|c|c|c|c|}
\hline \multirow[t]{2}{*}{ ID } & \multirow{2}{*}{$\begin{array}{l}\text { Monomers, } \\
\text { mole ratio }\end{array}$} & \multicolumn{2}{|c|}{ Polymer structure } & \multirow{2}{*}{$\begin{array}{c}\text { Char yield, } \\
\text { wt. \% }\end{array}$} & \multirow[t]{2}{*}{$\mathrm{XRD}$} \\
\hline & & silane & Carbosilane & & \\
\hline 138 & Ethyl & 100 & 0 & 25 & Amorphous \\
\hline 139 & Allyl & 80 & 20 & 35 & $\begin{array}{c}\text { Amorphous, } \\
\beta-\text { SiC }\end{array}$ \\
\hline 137 & Vinyl & 20 & 80 & 59 & $\begin{array}{c}\text { Amorphous, } \\
\beta \text {-SiC (minor) }\end{array}$ \\
\hline 154 & 35 Methyl/65 vinyl & 50 & 50 & 61 & $\begin{array}{l}\text { Amorphous, } \\
80 \text { A } \beta-\text { SiC }\end{array}$ \\
\hline 156 & 55 Methyl/45 vinyl & 70 & 30 & 61 & $\begin{array}{l}\text { Amorphous, } \\
90 \text { A } \beta-\text { SiC }\end{array}$ \\
\hline 155 & 75 Methyl/25 vinyl & 85 & 15 & 73 & 95 A $\beta$-SiC \\
\hline 161 & Methyl & 100 & 0 & 68 & 140 A $\beta-S i C$, \\
\hline 172 & Methyl + ethyl & 100 & 0 & $51-52$ & $\begin{array}{c}\beta-\operatorname{sic}, \quad s i \\
\text { (minor) }\end{array}$ \\
\hline 173 & Ethyl + vinyl & 60 & 40 & $45-50$ & $\beta-$ Sic \\
\hline 174 & $\begin{array}{l}\text { Methyl + vinyl } \\
\text { (insol.) }\end{array}$ & 75 & 25 & $71-72$ & $\beta$-SiC \\
\hline
\end{tabular}

TABLE II. - CONVERSION OF POLYMER TO CERAMIC

\begin{tabular}{|c|c|c|c|c|c|}
\hline \multirow{2}{*}{ ID } & Polymer & \multicolumn{3}{|c|}{$\begin{array}{c}\text { Ceramic } \\
\text { composition, } \\
\text { weight percent }\end{array}$} & Comments \\
\cline { 3 - 6 } & & Si & C & ${ }^{b}$ C & \\
\hline \multirow{2}{*}{138} & Ethyl & 60 & 27 & -- & ----------- \\
139 & Allyl & 65 & 27 & -- & ---------- \\
137 & Vinyl & 58 & 39 & -- & C rich \\
154 & 35 Methyl/65 vinyl & 63 & 31 & 33 & ------------ \\
156 & 55 Methyl/45 vinyl & 66 & 28 & 32 & ----------- \\
155 & 75 Methyl/25 vinyl & 66 & 27 & 28 & Choice for SiC \\
161 & Methyl & 69 & 25 & 26 & Free Si \\
172 & Methyl + ethyl & 70 & 27 & 26 & Free Si \\
173 & Ethyl + vinyl & 62 & 32 & 34 & ------------ \\
174 & Methyl + vinyl & 64 & 31 & 30 & Insoluable \\
\hline
\end{tabular}

${ }^{a}$ Stoichiometric $\mathrm{SiC}$ is $70 \mathrm{Si}, 30 \mathrm{C}$ by weight.

b Induction furnace method. 


$$
\begin{aligned}
& \underset{\text { Metathesis }}{\longrightarrow} \mathrm{H}_{3} \mathrm{Si}-\mathrm{CH}=\mathrm{CH}-\mathrm{SiH}_{3} \rightarrow {\left[\mathrm{HSi}-\mathrm{CH}_{2}-\mathrm{CH}_{2}-\mathrm{SiH}\right] } \\
& \text { (and others) }
\end{aligned}
$$
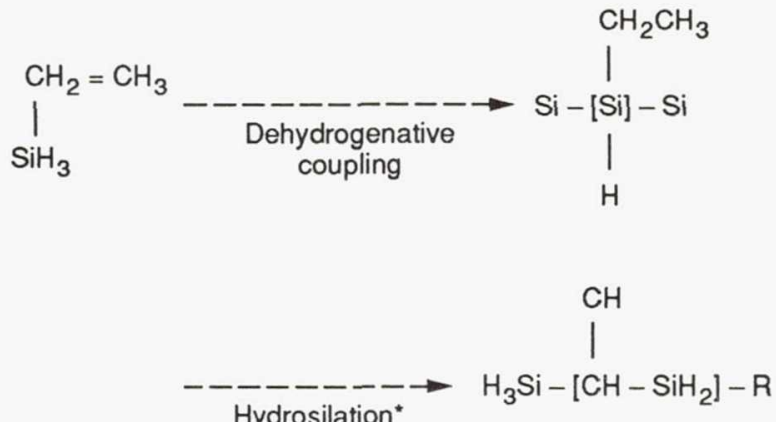

Hydrosilation*

- Major reaction path

Figure 1.-Proposed polymerization mechanisms for the polymerization of vinylsilane using a titanocene catalyst.

$$
\begin{aligned}
& \mathrm{RSi}\left(\mathrm{OCH}_{3}\right)_{3} \underset{\text { Esterification }}{\stackrel{\text { Hydrolysis }}{\rightleftharpoons}} \mathrm{RSi}(\mathrm{OH})_{x}\left(\mathrm{OCH}_{3}\right)_{3-x}+\mathrm{xCH}_{3} \mathrm{OH} \\
& \mathrm{R} \text { = Phenyl, or methyl } \\
& =\mathrm{Si}-\mathrm{OCH}_{3}+\mathrm{HO}-\mathrm{Si}=\underset{\text { Alcoholysis }}{\stackrel{\text { Condensation }}{\rightleftharpoons}}=\mathrm{Si}-\mathrm{O}-\mathrm{Si}=+\mathrm{CH}_{3} \mathrm{OH}
\end{aligned}
$$

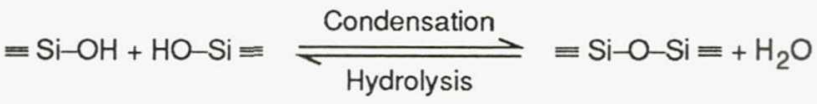

Variables: $\mathrm{pH}, \mathrm{H}_{2} \mathrm{O} /-\mathrm{OCH}_{3}$, phenyl/methyl

Figure 2.-Reactions involved in the synthesis of polysilsesquioxanes.

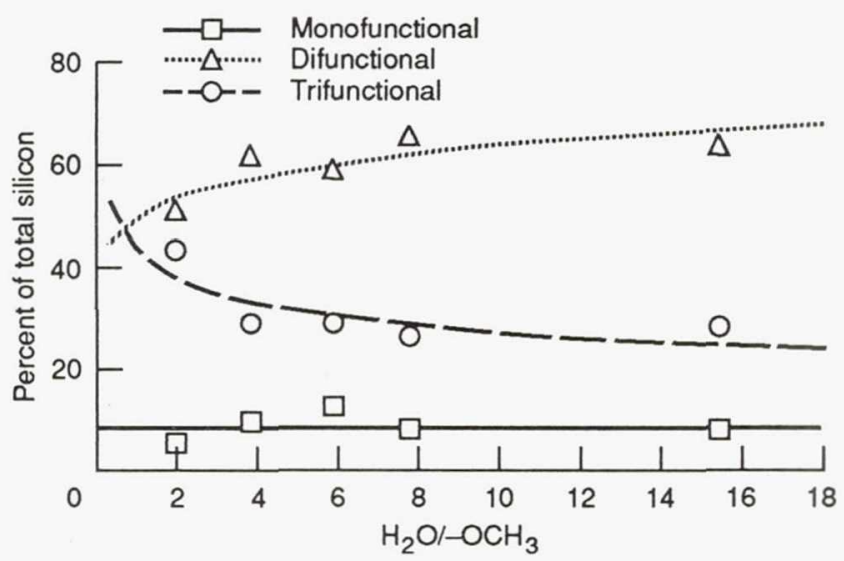

Figure 3.-Influence of water/methoxy ratio on polysilsesquioxane structure. 


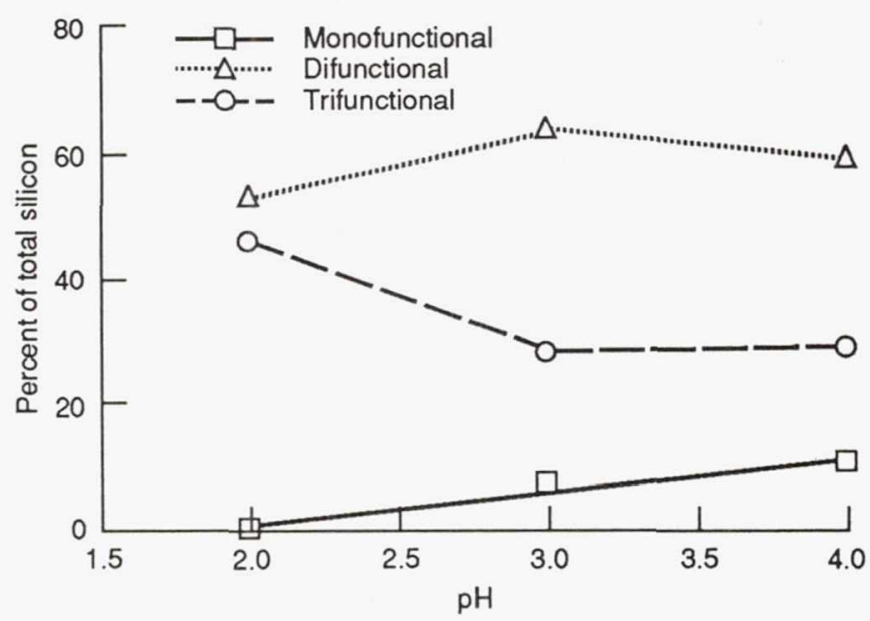

Figure 4.--Variation in polysilsesquioxane structure with $\mathrm{pH}$ at which the polymer was synthesized.

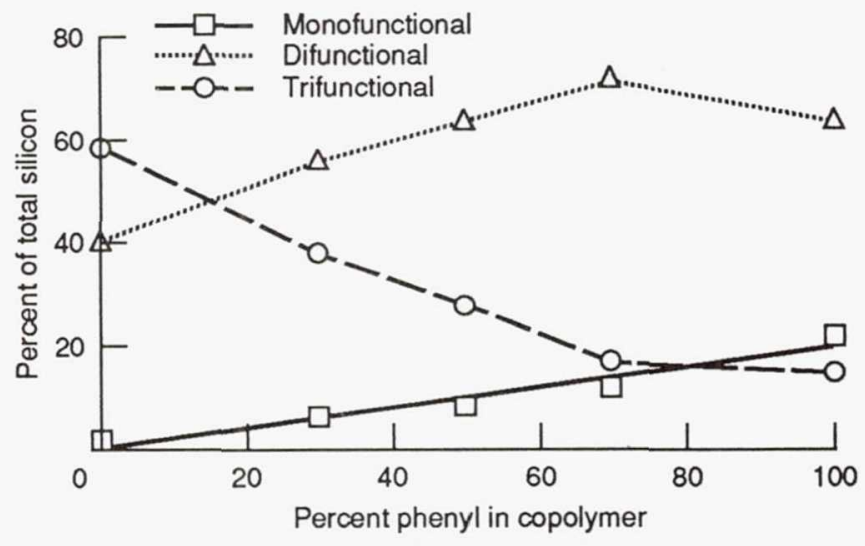

Figure 5.-Dependence of polysilsesquioxane structure on phenyl/methyl ratio of monomer reactants.

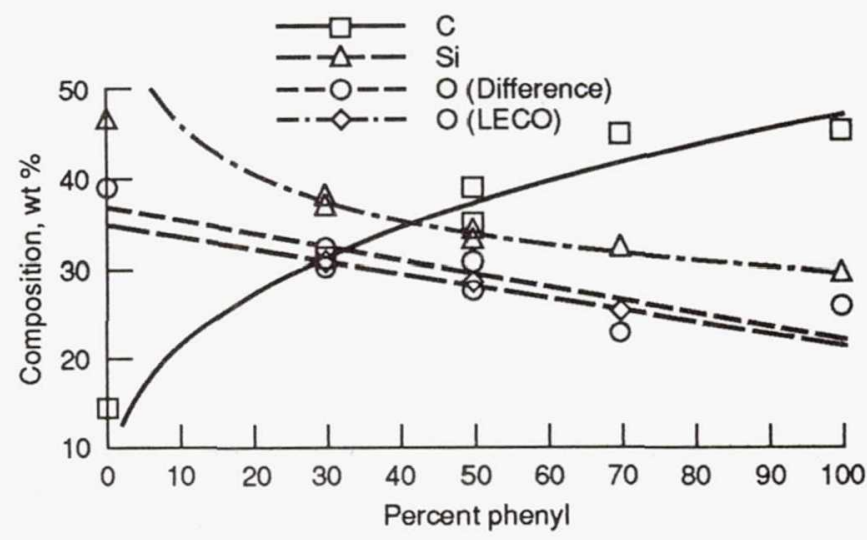

Figure 6.-Variation in ceramic composition with phenyl content of polysilsesquioxane precursor. 


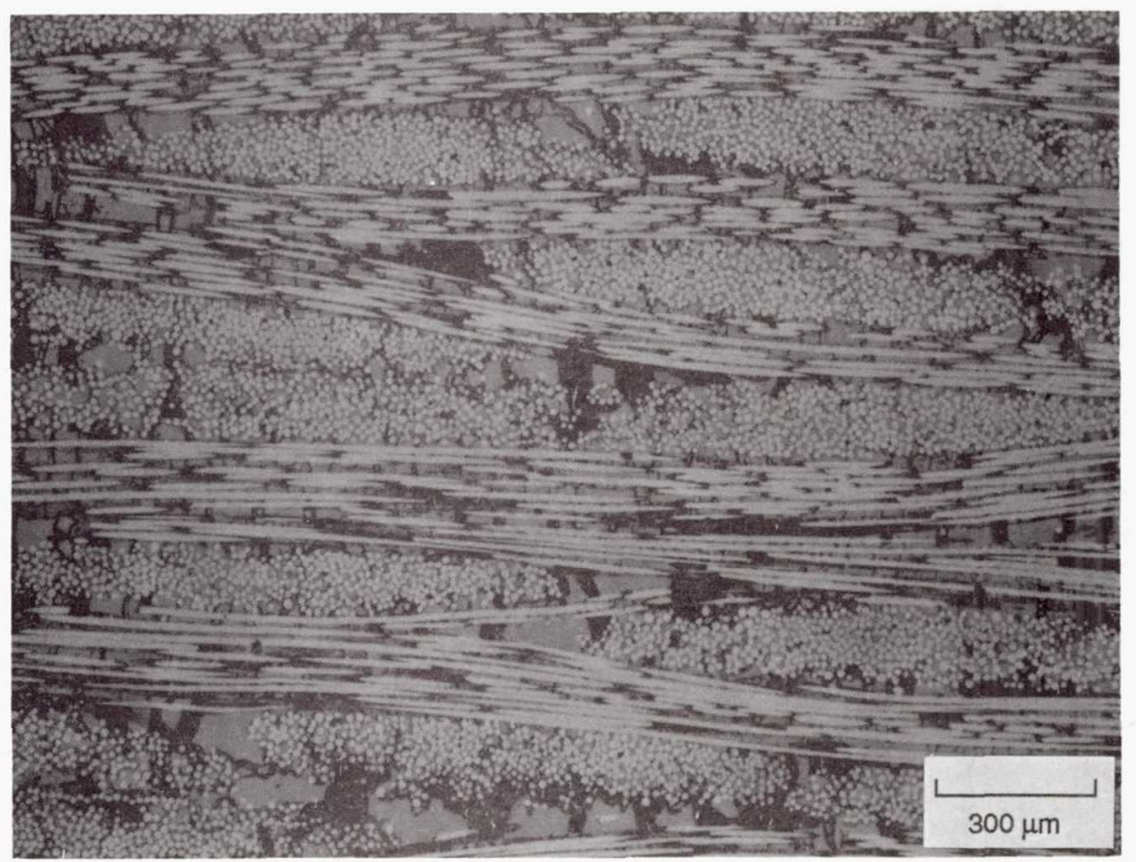

Figure 7.-Polished cross-section of Nicalon/Si-C-O composite.

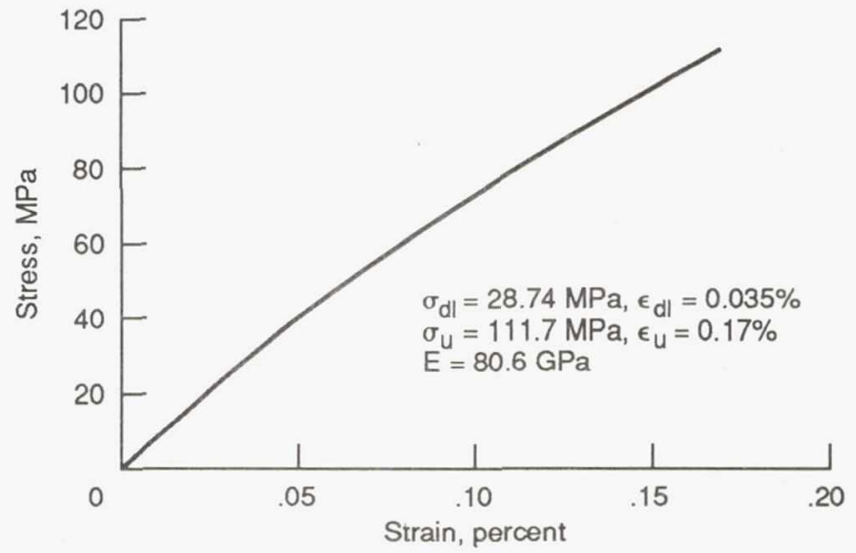

Figure 8.-Typical room temperature tensile stress-strain behavior of Nicalon/Si-C-O composite having eight harness satin weave. 

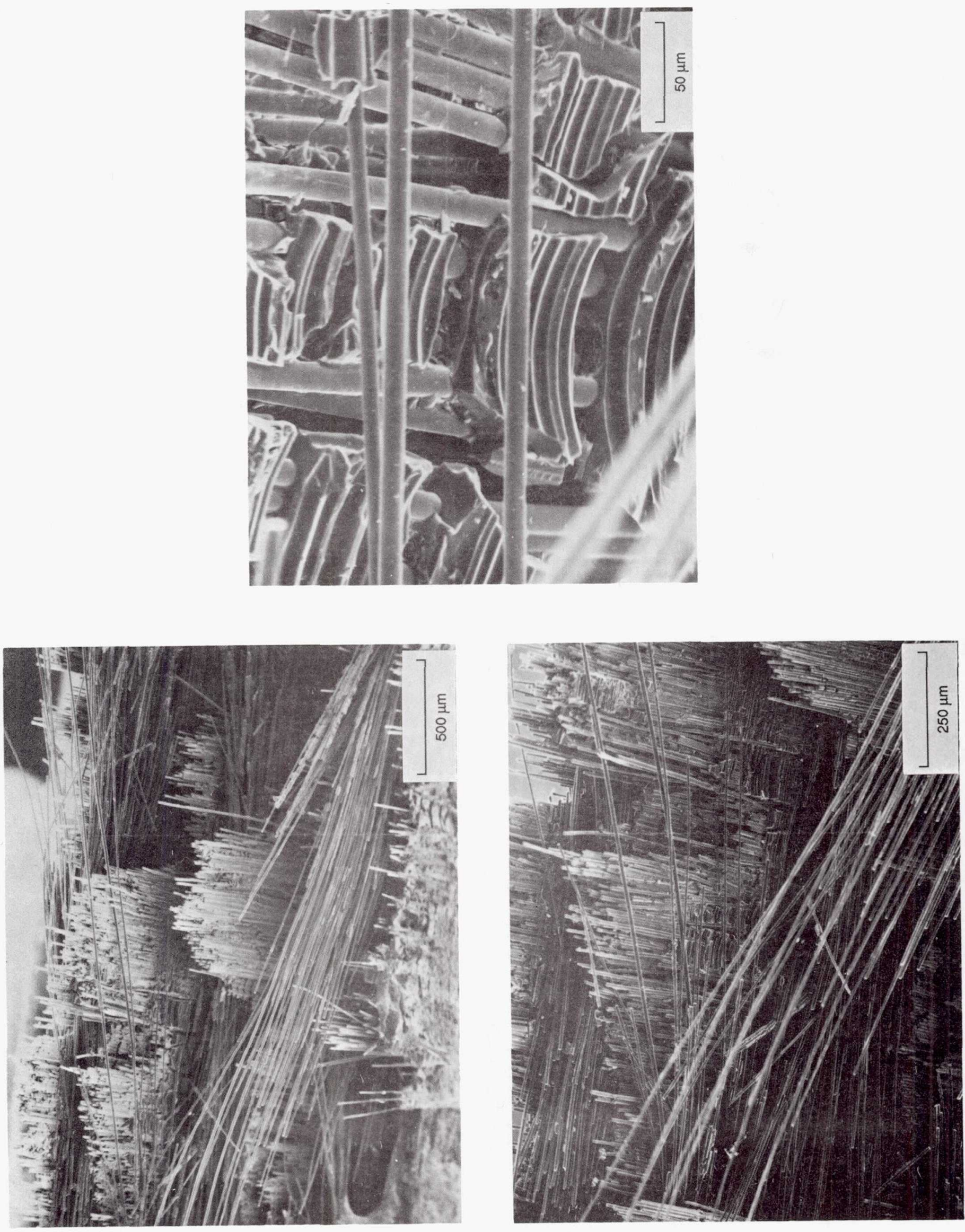

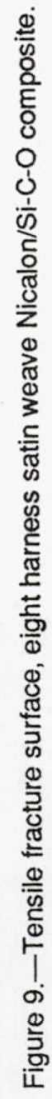



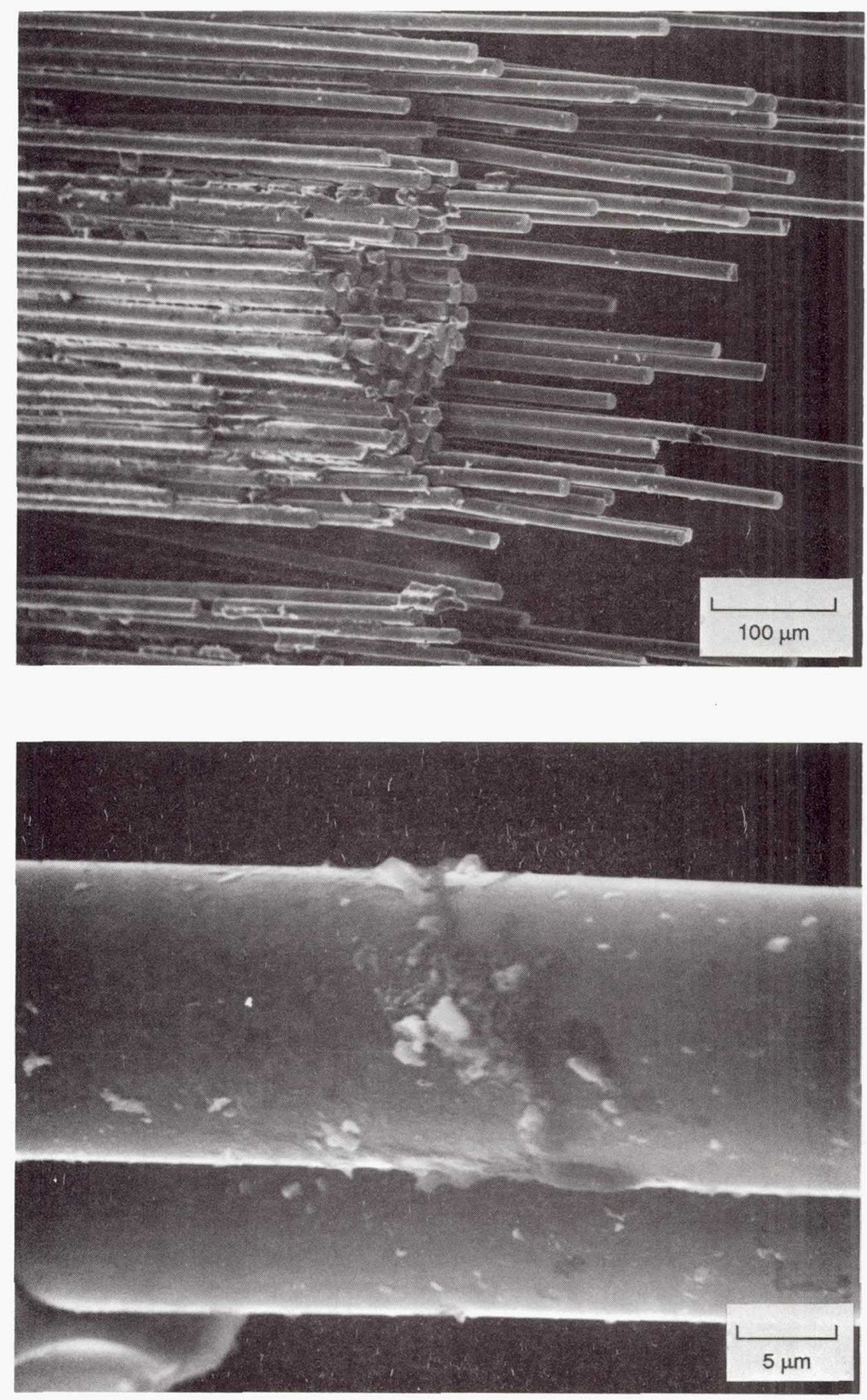

Figure 10.-Enlargement of fracture surface to show fiber bundle fracture and adhesion of matrix to fiber. 


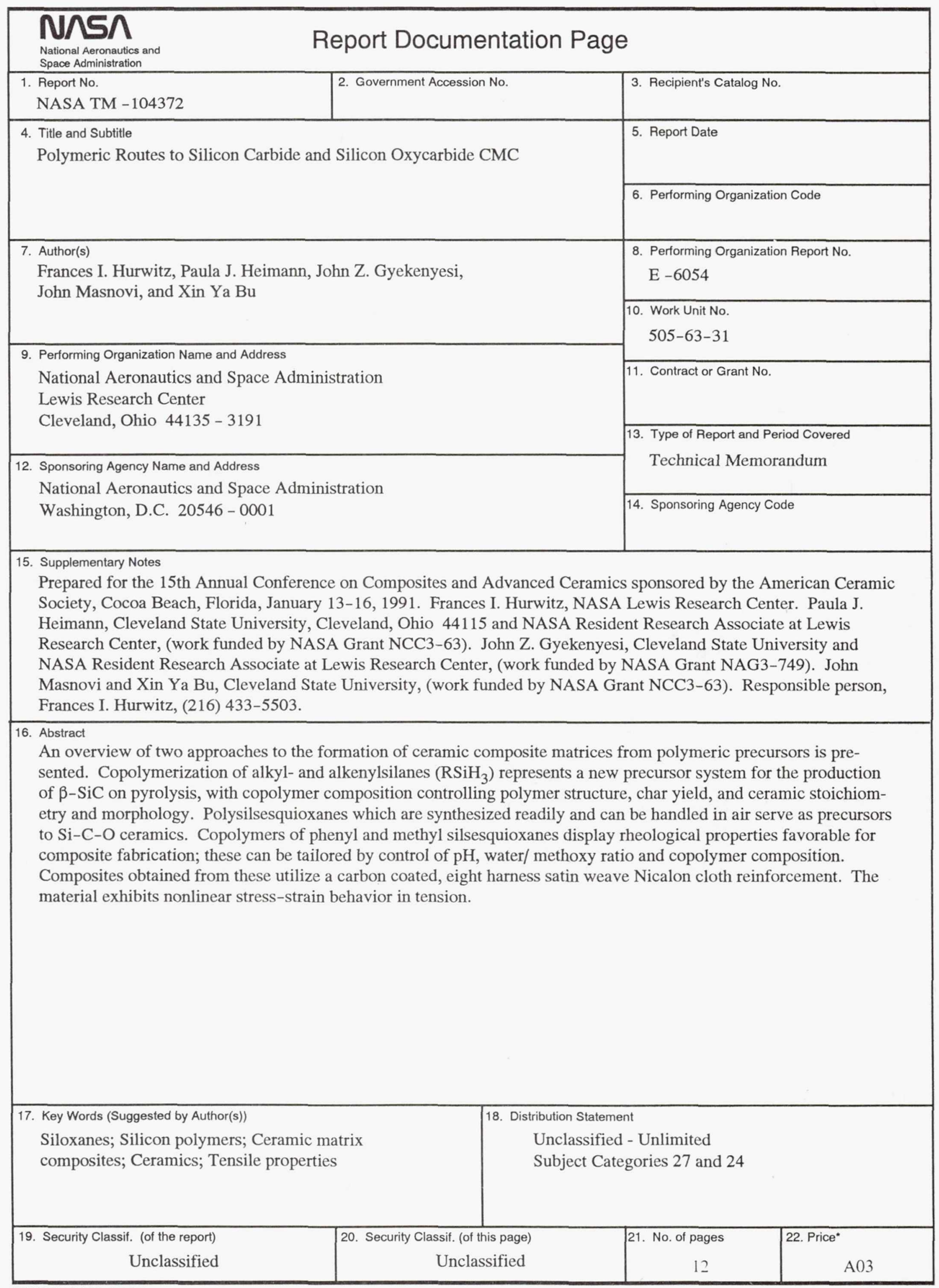

